\title{
Transfer Effects as a Function of Sequential and Quantitative Schedule Constraints
}

\author{
Hans-Joachim Grabitz \& Marianne HammerL \\ Heinrich-Heine-University Duesseldorf, Germany
}

\begin{abstract}
Schwartz $(1982,1988)$ found that a pretraining of contingent reinforcement interferes with subsequent rule discovery. The present study investigated the effects of schedule imposed sequential and quantitative constraints (Timberlake \& Allison, 1974) on task performance in a subsequent test phase. Sixty-four Ss, students of the University of Duesseldorf, were assigned at random to one of four experimental conditions, differing according to the presence vs. absence of sequential and quantitative constraints, respectively. Discrimination-learning performance and variability during test phase were significantly better for Ss experiencing sequential constraint during treatment. In contrast, the introduction of a quantitative restriction during treatment had no statistically significant effects on test phase performance.
\end{abstract}

Key Words - Operant conditioning, stereotypy, response deprivation approach, humans.

OVER THE LAST TWO DECADES, there has been an increasing interest in assessing whether contingent reinforcement might have some undesirable side effects. Vogel and Annau (1973) reported reinforcement-induced sequence stereotypy in pigeons. Further experiments by Schwartz (1982) revealed that like pigeons, college students develop strong sequence stereotypy even when the reinforcement contingency does not require stereotypy. And, more important, Schwartz (1982) found that a history of reinforcement for successful sequences seems to interfere with subsequent rule discovery.

Despite a considerable number of studies, the answer to the question of what actually produces negative transfer effects of contingent reinforcement remains far from clear. Gross and Gutman (1988) for example report that occurrence of negative transfer was not strongly related to prior presence or absence of stereotypy or to prior reinforcement schedule (i.e., continuous vs. partial reinforcement).

The present study focuses on the effects of the restrictions that are imposed by a schedule on free baseline responding. An analysis of what happens when a reinforcement schedule is imposed on unconstrained behavior emerges from the "response deprivation approach" (Timberlake \& Allison, 1974). According to this model, a schedule imposes sequential and quantitative constraints, which conflict with the patterns of free behavior. The requirement of performing an instrumental response (I) in order to gain access to a contingent response (C) constitutes a sequential restriction. A quantitative restriction occurs if the subjects, by maintaining instrumental responding at its baseline level, would fall below baseline level of access to the contingent response. The aim of the present experi-

Address for correspondence: Hans-Joachim Grabitz, Dept. of Psychology, Heinrich-Heine-University Duesseldorf, Universitaetsstr. 1, D-4000 Duesseldorf 1, Germany.

Integrative Physiological and Behavioral Science, April-June, 1993, Vol. 28, No. 2, 182-185. 
ment was to investigate the effects of the imposition of these constraints on free baseline responding on task performance in a subsequent test phase.

\section{Method}

Thirty-two female and thirty-two male students of the University of Duesseldorf served as paid participants. Experimental sessions were conducted on a Commodore PC 10 microcomputer in a room containing a table and chair. Subjects were tested individually. There were three phases: baseline, treatment, and test. During baseline and treatment, lasting for $30 \mathrm{~min}$ each, subjects sat at the table in front of a response console and a video display. Their task during these phases was playing video games. Three different games were offered as response alternatives that could be chosen freely during baseline. Subjects were instructed how to use manipulanda in order to choose and play each game. The duration of each game and the sequence in which games were chosen were recorded.

At the beginning of the treatment phase, female and male subjects were randomly assigned to one of four groups. Group 1 (Control) continued with baseline conditions. For each subject of the remaining three groups, the video games were assigned at random to serve as instrumental (I), contingent (C), or alternative (A) responses. The constraints imposed on free baseline responding during treatment were "sequential restriction" (S) for Group 2, "quantitative restriction" (Q) for Group 3 and "sequential and quantitative restriction" (SQ) for Group 4. For Group 2, access to the contingent response was made dependent on the prior performance of the instrumental response. However, performing baseline amount of instrumental response gained access to full baseline amount of contingent response. The same conditions held for Group 4, except that performing baseline amount of instrumental response gained access to only half baseline amount of contingent response. In order to approach the baseline amount of contingent response, subjects of Group 4 would have to increase their instrumental responding above baseline amount. The conditions of Group 3, quantitative restrictions without sequential dependency of responses, are difficult to establish due to the fact that the subjects-like subjects of Group 4-should have the possibility to return to their baseline amount of contingent response. Group 3, therefore, received access to full baseline amount of contingent response, but as a total at the end of the treatment phase.

Two different tasks, "Discrimination learning" and "Searching three-term-sequences" were used to test for transfer effects. The tasks were presented in a counterbalanced order. Discrimination tasks required subjects to sit at the table in front of two consoles containing a red and a green light near the top and an operative button each. Subjects were told that their task was to discover the relation between the different patterns of lights lit and appropriate responses (e.g., "Push the left button if the light(s) lit are green, push the right button if the light(s) lit are red."). Following subjects' response, all lights were extinguished and feedback was given concerning correctness of responses. Then, with a separate button, subjects initiated the next trial. Six different rules were presented for $120 \mathrm{~s}$ each.

For searching three-term-sequences, subjects sat in front of three consoles A, B, and C with a light and an operative button each. The task required the subject to find a preprogrammed sequence of responses (e.g., $\mathrm{CAB}, \mathrm{BCC}$, etc.). A trial consisted of three responses. After three responses to any button, all lights were extinguished, feedback concerning the correctness of subjects' response sequence was given, and a new trial had to be started by pushing a separate button. Ten different sequence tasks were presented for 
TABLE 1. Mean Number of Choosing the Instrumental (I), Contingent (C), and Alternative (A) Response and Mean Number of Transitions From $I$ to $C(I \rightarrow C)$ and $I$ to $A(I \rightarrow A)$ During Baseline (Basel.) and Treatment (Treat.)

\begin{tabular}{|c|c|c|c|c|c|c|c|c|}
\hline Response & \multicolumn{2}{|c|}{ (Control) } & \multicolumn{2}{|c|}{$(S)^{\text {Group }}$} & \multicolumn{2}{|c|}{ (Q) } & \multicolumn{2}{|c|}{$(S Q)$} \\
\hline $\begin{array}{l}\text { I } \\
\text { C } \\
\text { Diff: } \\
\mathbf{A} \\
(\mathbf{I}-\mathbf{A})\end{array}$ & $\begin{array}{r}\text { Basel. } \\
2.94 \\
3.00 \\
3.06 \\
-0.12\end{array}$ & $\begin{array}{l}\text { Treat. } \\
2.25 \\
1.87 \\
1.69 \\
0.56\end{array}$ & $\begin{array}{c}\text { Basel. } \\
3.25 \\
3.13 \\
2.93 \\
0.34\end{array}$ & $\begin{array}{c}\text { Treat. } \\
3.53 \\
2.26 \\
2.53 \\
1.00\end{array}$ & $\begin{array}{l}\text { Basel. } \\
3.00 \\
3.06 \\
2.75 \\
0.25\end{array}$ & $\begin{array}{c}\text { Treat. } \\
1.94 \\
1.12 \\
1.81 \\
0.13\end{array}$ & $\begin{array}{r}\text { Basel. } \\
2.94 \\
2.94 \\
3.00 \\
-0.06\end{array}$ & $\begin{array}{r}\text { Treat. } \\
4.56 \\
3.06 \\
3.50 \\
1.06\end{array}$ \\
\hline Diff: $\begin{array}{ll} & (\mathrm{I} \rightarrow \mathrm{C}) \\
& (\mathrm{I} \rightarrow \mathrm{A}) \\
(\mathrm{I} \rightarrow \mathrm{C})-(\mathrm{I} \rightarrow \mathrm{A})\end{array}$ & $\begin{array}{r}1.12 \\
1.19 \\
-0.07\end{array}$ & $\begin{array}{r}.75 \\
1.00 \\
-0.25\end{array}$ & $\begin{array}{r}1.20 \\
1.40 \\
-0.20\end{array}$ & $\begin{array}{l}2.13 \\
1.07 \\
1.06\end{array}$ & $\begin{array}{l}1.50 \\
0.81 \\
0.69\end{array}$ & $\begin{array}{r}.62 \\
1.00 \\
-0.38\end{array}$ & $\begin{array}{l}1.06 \\
1.06 \\
0.00\end{array}$ & $\begin{array}{l}3.06 \\
1.12 \\
1.94\end{array}$ \\
\hline
\end{tabular}

$120 \mathrm{~s}$ each. For four of the ten tasks, no correct sequence was preprogrammed. Subjects received the feedback "wrong" for at least the first 26 trials. These tasks served to test subjects' variability.

Percent of correct responses for the last $60 \mathrm{~s}$ of discrimination tasks, number of threeterm-sequences found, and variability were the major dependent measures. As a measure for variability, number of different response sequences relative to the according number of trials (max. 27) was used.

\section{Results}

Table 1 contains the mean number of choosing the responses I, C, and A during baseline and treatment. Additionally, the mean frequencies for changes (transitions) from I to $\mathrm{C}$ and I to $A$ are shown. As can be seen, the frequency for choosing I as compared to choosing $A$ (I-A) during treatment was higher for Groups S and SQ. Though this main effect was not statistically significant (Mann-Whitney $U: p=.0594$ ), it shows possible influences of sequential constraint. There was a significant effect of sequential constraint for the difference of $(\mathrm{I} \rightarrow \mathrm{C})-(\mathrm{I} \rightarrow \mathrm{A})$ during treatment (Mann-Whitney $U: p=.00017)$. However, there were no significant differences among groups for the variation of quantitative constraint.

Table 2 shows that discrimination performance was better (Mann-Whitney $U: p=$ $.0106)$ for groups receiving sequential constraint during treatment (Groups $S$ and $S Q$ ). Again, no effect was found for quantitative restriction. Similar patterns of results appeared for the number of three-term-sequences discovered and variability ratios. While differences among groups concerning three-term-sequences were statistically not significant, there was a significant main effect of sequential constraint for variability ratios (MannWhitney $U: p=.0027$ ), with increased variability for Groups S and SQ.

\section{Discussion}

The present study provides evidence that negative transfer effects are not the inevitable result of the restrictions associated with establishing a reinforcement schedule. In contrast, the imposing of a sequential constraint on free baseline behavior seems to improve subjects' discrimination learning performance and their variability while searching sequences. Because no negative transfer effects were found, the present data do not help much to find 
TABle 2. Mean Percent of Correct Discriminative Responses, Mean Number of Three-termsequences Discovered, and Mean Variability Ratios

\begin{tabular}{|c|c|c|c|c|}
\hline \multirow[b]{2}{*}{ Test performance } & \multirow[b]{2}{*}{ (Control) } & \multicolumn{2}{|c|}{ Group } & \multirow[b]{2}{*}{$(S Q)$} \\
\hline & & (S) & (Q) & \\
\hline Discrimination & 67.18 & 79.95 & 72.18 & 78.30 \\
\hline Three-term-sequences & 4.81 & 5.31 & 4.75 & 5.56 \\
\hline Variability & .6539 & .7690 & .7082 & .7869 \\
\hline
\end{tabular}

the sources of those negative effects. Another question is, why sequential restrictions should have positive effects on performance in subsequent tasks. One possible answer is that the regaining of the lost access to the contingent response by performing the instrumental response is responsible for this effect. Another view is that sequential restrictions are not necessarily experienced as constraints, since sequential restrictions constitute what is described in other words as contingency between response and reinforcer. And, as learned helplessness research suggests, contingency provides control.

\section{References}

Gross, D.K., \& Gutman, A. (1988). Effects of schedule and length of training on reward-induced stereotypy and negative transfer in humans. The Psychological Record, 38, 567-594.

Schwartz, B. (1982). Reinforcement-induced behavioral stereotypy: How not to teach people to discover rules. Journal of Experimental Psychology: General, 111, 23-59.

Schwartz, B. (1988). The experimental synthesis of behavior: Reinforcement, behavioral stereotypy, and problem solving. In G.H. Bower (Ed.), The psychology of learning and motivation (Vol. 22, pp. 93-138). New York: Academic Press.

Timberlake, W., \& Allison, J. (1974). Response deprivation: An experimental approach to instrumental performance. Psychological Review, 81, 146-164.

Vogel, R., \& Annau, Z. (1973). An operant discrimination task allowing variability of response patterning. Journal of the Experimental Analysis of Behavior, 20, 1-6. 